\title{
Faktor Risiko Ibu Pada Bayi Berat Lahir Rendah
}

\section{Maternal Risk Factors For Low Birth Weight Neonates}

\author{
Fayakun Nur Rohmah ${ }^{1, *}$, Tri Hapsari Listyaningrum ${ }^{2}$ \\ ${ }^{1,2}$ Universitas 'Aisyiyah Yogyakarta, Jalan Ring Road Barat No. 63 Nogotirto, Gamping, Sleman , Yogyakarta, \\ 55292, Indonesia \\ ${ }^{1}$ fayakun.nurrohmah@unisayogya.ac.id*; ${ }^{2}$ trihapasari_listyaningrum@unisayogya.ac.id \\ * corresponding author \\ Tanggal Submisi: 3 Januari 2021, Tanggal Penerimaan: 1 Maret 2021
}

\begin{abstract}
Abstrak
Komplikasi yang menjadi penyebab kematian terbanyak yaitu asfiksia, bayi berat lahir rendah (BBLR), dan infeksi. Persentase kematian neonatal pada BBLR pada tahun 2019 di Indonesia sebanyak 35,3\%. Penelitian bertujuan untuk mengetahui faktor risiko ibu pada kejadian BBLR. Penelitian ini menggunakan metode deskriptif dengan pendekatan retrospektif, sempel diambil dengan total sampling yaitu bayi yang lahir dengan berat badan kurang dari 2500 gram di RS PKU Muhammadiyah Yogyakarta pada tahun 2017 sebanyak 75 bayi. Hasil penelitian menunjukkan faktor Ibu mayoritas ibu berumur 20-35 tahun sebanyak 60 orang (80\%), dan ibu multigravida sebanyak 41 ibu $(54,7 \%)$.
\end{abstract}

Kata kunci : BBLR; Faktor resiko ibu

\begin{abstract}
The complications that caused the most deaths were asphyxia, low birth weight babies (LBW), and infections. The percentage of mortality LBW in 2019 in Indonesia was 35,3\%. The aim of the study was to determine maternal risk factors for LBW. This study used a descriptive method with a retrospective approach, the sample was taken with total sampling, namely babies born with body weight less than 2500 grams in PKU Muhammadiyah Hospital in Yogyakarta in 2017 as many as 75 babies. The results showed that the majority of mothers aged 20-35 years were 60 people (80\%), and multigravida mothers were 41 mothers $(54.7 \%)$.
\end{abstract}

Keywords: LBW; maternal risk factor

\section{PENDAHULUAN}

Kematian neonatal ini menggambarkan tingkat pelayanan kesehatan ibu dan anak. Komplikasi yang menjadi penyebab kematian neonatal terbanyak yaitu Berat Badan Lahir Rendah BBLR (35,3\%), asfiksia (27,0\%), kelainan bawaan (21,4\%), sepsis (12,5\%), tetanus neonatorum $(3,5 \%)$ dan lain-lain $(0,3 \%)$ (Kementrian Kesehatan RI, 2020). Persentase BBLR di Daerah IstimewaYogyakarta pada tahun 2018 sebesar 5,52 \% dan 2019 sesesar 5,7\% cenderung meningkat dari tahun 2017 yaitu 4,86\% (Dinas Kesehatan DIY, 2020). BBLR berakibat pada gangguan perkembangan fisik, dan pertumbuhannya dapat terhambat jika tidak mendapatkan penanganan yang adekuat. Bahkan BBLR menjadi salah satu risiko terjadinya stunting yang masih menjadi masalah besar di Indonesia (Aryastami \& Tarigan, 2017). BBLR berdampak pula terhadap gangguan perkembangan mental, diketahui bahwa tingkat kecerdasan anak yang lahir BBLR lebih rendah dibandingkan dengan anak yang lahir dengan berat badan lahir normal. Pada usia dewasa Bayi BBLR berisiko mengalami penyakit kardiovaskular, diabetes mellitus dan obesitas (Mitra, 2014).

BBLR disebabkan oleh usia kehamilan yang pendek (prematuritas), IUGR (Intra 
Uterine Growth Restriction) atau keduanya. Kedua penyebab ini dipengaruhi oleh faktor risiko, seperti faktor ibu, plasenta, janin dan lingkungan. Faktor ibu diantaranya adalah paritas dan umur ibu, status gizi ibu, anemia, dan kenaikan berat badan selama kehamilan (Kosim MS, Yunanto A, Dewi R, Sarosa GI, 2012).

Kehamilan yang berulang-ulang akan menyebabkan kerusakan pada dinding pembuluh darah uterus, hal ini akan mempengaruhi nutrisi ke janin pada kehamilan selanjutnya sehingga dapat menyebabkan gangguan pertumbuhan janin yang selanjutnya akan melahirkan bayi dengan BBLR (Khoiriah, 2017). Paritas merupakan faktor resiko tinggi penyebab BBLR, dimana ibu dengan paritas >3 anak akan beresiko 6,4 kali melahirkan BBLR (Ekowati et al., 2017). Ibu yang memiliki umur berisiko berpeluang 4,3 kali lebih besar terjadinya bayi berat lahir rendah dibandingkan usia yang tidak beresiko(Khoiriah, 2017). Persentase tertinggi bayi dengan berat badan lahir rendah terdapat pada kelompok remaja dan wanita berusia lebih dari 40 tahun (Makbruri, 2015). Remaja yang hamil berpeluang 7 kali lipat melahirkan bayi BBLR (A. Rahayu et al., 2018).

Pemerintah dalam peta jalan SDGs Indonesia menargetkan angka kematian bayi 12 kematian per 1000 kelahiran hidup pada tahun 2030 (Kementerian Perencanaan dan Pembangunan Nasional, 2019). Pemerintah mengupayakan penanganan BBLR sesuai dengan standar oleh tenaga kesehatan (dokter, bidan atau perawat) terlatih baik di rumah, sarana pelayanan kesehatan dasar maupun sarana pelayanan kesehatan rujukan. Pelayanan sesuai standar antara lain sesuai dengan standar MTBM, Manajemen Asfiksia Bayi Baru Lahir, Manajemen Bayi Berat Lahir Rendah, pedoman pelayanan neonatal essensial di tingkat pelayanan kesehatan dasar, PONED, PONEK atau standar operasional pelayanan lainnya(Kemenkes RI, 2016). Salah satu bentuk program pemerintah adalah pemberian makanan tambahan pada balita dan ibu hamil. Fokusnya adalah pada zat gizi makro maupun mikro bagi balita dan ibu hamil yang sangat diperlukan untuk pencegahan (BBLR) dan balita stunting (Kementerian Kesehatan Republik Indonesia, 2018). Hal pokok yang juga menjadi perhatian adalah pemberian ASI yang adekuat untuk BBLR. Menyusui bayi BBLR memiliki tingkat kesulitan yang tinggi. Dukungan pemberian asi dipengaruhi oleh berbagai tradisi yang dipercayai keluarga dan lingkungan sosial (Choiriyah et al., 2015). Keberhasilan pemberian asi pada ibu dengan dukungan keluarga yang kuat akan berdampak pada pemberian asi ekslusif (Yuliawati et al., 2018).

Mengingat perlunya perhatian terhadap permasalahan BBLR yang masih menjadi salah satu komplikasi penyebab kematian bayi di Indonesia, maka peneliti tertarik mencari gambaran faktor risiko Ibu yang pada kejadian BBLR di PKU Muhammadiyah Yogyakarta tahun 2017.

\section{METODE PENELITIAN}

Jenis penelitian ini adalah penelitian deskriptif dengan pendekatan retrospektif, sempel pada penelitian ini adalah bayi yang lahir dengan berat badan kurang dari 2500 gram di RS PKU Muhammadiyah Yogyakarta pada tahun 2017 dengan teknik pengambilan sampel menggunakan total sampling sebanyak 75 bayi. Data diambil dari Rekam medis pasien kemudian dilakukan analisis distribusi frekuensi dengan SPSS 21.

\section{HASIL DAN PEMBAHASAN}

1. Derajat BBLR

Tabel 1. Kejadian BBLR

\begin{tabular}{lcc}
\hline \multicolumn{1}{c}{ Derajat BBLR } & Frekuensi & Persentase $(\%)$ \\
\hline BBLR $(1500-2499$ gr $)$ & 67 & 89,33 \\
BBLSR $(1000-1499$ gr $)$ & 6 & 8 \\
BBLER $(<1000$ gr $)$ & 2 & 2,67 \\
\hline
\end{tabular}




\begin{tabular}{lll}
\hline Jumlah & 75 & 100
\end{tabular}

Mayoritas BBLR berdasarkan derajatnya masuk dalam kategori BBLR dengan berat badan bayi 1500-2499 gram yaitu sebanyak 67 bayi ( $89,33 \%)$

2. Faktor Ibu

Tabel 2. Distribusi Frekuensi Faktor Ibu pada kejadian BBLR

\begin{tabular}{lcc}
\hline Faktor & Frekuensi & Persentase $(\boldsymbol{\%})$ \\
\hline Umur & 5 & \\
$<20$ tahun & 50 & 6,67 \\
$20-35$ tahun & 20 & 66,67 \\
$>35$ tahun & & 26,66 \\
\hline Paritas & 30 & 40 \\
Primigravida & 41 & 54,7 \\
Multigravida & 4 & 5,3 \\
Grandemultigravida & 75 & 100 \\
Jumlah & & \\
\hline
\end{tabular}

Mayoritas ibu yang melahirkan anak BBLR berumur 20-35 tahun yaitu sebanyak 50 orang $(66,67 \%)$, dan paritas tertinggi adalah multigravida yaitu sebanyak $41 \mathrm{ibu}(54,7 \%)$.

3. Tabulasi silang

Tabel 3. Tabulasi silang Derajat BBLR dan faktor ibu

\begin{tabular}{|c|c|c|c|c|c|c|c|c|}
\hline \multirow{3}{*}{ Faktor } & \multicolumn{8}{|c|}{ Derajat BBLR } \\
\hline & \multicolumn{2}{|c|}{ BBLR } & \multicolumn{2}{|c|}{ BBLSR } & \multicolumn{2}{|c|}{ BBLER } & \multicolumn{2}{|c|}{ Total } \\
\hline & $\mathbf{f}$ & $\%$ & f & $\%$ & f & $\%$ & f & $\%$ \\
\hline \multicolumn{9}{|l|}{ Paritas } \\
\hline Primipara & 28 & 93.3 & 2 & 6.7 & 0 & 0 & 30 & 100 \\
\hline Multipara & 37 & 90.2 & 2 & 4.9 & 2 & 4.9 & 41 & 100 \\
\hline Graden & 2 & 50 & 2 & 50 & 0 & 0 & 4 & 100 \\
\hline \multicolumn{9}{|l|}{ Umur } \\
\hline$<20$ tahun & 5 & 100 & 0 & 0 & 0 & 0 & 5 & 100 \\
\hline 20-35 tahun & 44 & 88 & 5 & 10 & 1 & 2 & 50 & 100 \\
\hline$>35$ tahun & 18 & 90 & 1 & 5 & 1 & 5 & 20 & 100 \\
\hline Total & 67 & 89.3 & 6 & 8 & 2 & 2.7 & 75 & 100 \\
\hline
\end{tabular}

a. Faktor risiko umur Ibu pada bayi BBLR

Tabel 3 menunjukkan data tabulasi silang antara faktor risiko umur ibu dengan derajat BBLR. Mayoritas bayi BBLR dilahirkan oleh ibu yang berumur 20-35 tahun sebanyak 44 bayi dari 75 BBLR. Hasil uji statistik menggunakan spearmen rank menunjukkan hasil $\mathrm{p}=0,564$ > 0,05 artinya tidak ada hubungan antara umur ibu dengan derajat BBLR. Sejalan dengan penelitian yang lalu bahwa tidak ada hubungan antara umur ibu dengan berisiko dan tidak berisiko dengan derajat BBLR (Berat Badan Lahir Rendah (BBLR), Berat Badan Lahir Sangat Redah (BBLSR) dan Berat Badan Lahir Ekstrim Rendah (BBLER) (Dwi Ertiana, 2020; Y. Rahayu et al., 2015).

Berkaitan dengan kejadian BBLR tanpa melihat derajat BBLR, menurut penelitian terdahulu Ibu yang memiliki umur beresiko berpeluang 4,290 kali lebih besar terjadinya bayi berat lahir rendah dibandingkan usia yang tidak beresiko (Khoiriah, 2017). Persentase tertinggi 
bayi dengan berat badan lahir rendah terdapat pada kelompok remaja dan wanita berusia lebih dari 40 tahun. Umur ibu $<20$ tahun merupakan faktor resiko kejadian BBLR. Ibu umur yang muda umumnya kurang paham dalamasuhan perawatan dan asupan nutrisi kehamilan (Makbruri, 2015). Sejalan dengan penelitian lain bahwa presentase kejadian BBLR pada kehamilan remaja berumur $<20$ tahun lebih berisiko melahirkan BBLR dibandingkan dengan ibu yang berusia 20-34 tahun(Siramaneerat et al., 2018). Sekitar 20,1\% kehamilan remaja akan melahirkan BBLR (Bhaskar et al., 2015).

Usia muda merupakan faktor resiko tinggi terjadinya BBLR, karena wanita yang hamil umur dibawah 20 tahun perkembangan organ-organ reproduksi dan fungsi fisiologisnya belum optimal Organ reproduksi yang belum sempurna dapat mengakibatkan berkurangnya suplai aliran darah ke serviks dan uterus. Hal ini dapat mengakibatkan kurangnya nutrisi terhadap janin yang sedang tumbuh dan berkembang yang bisa mengarah ke kondisi bayi saat dilahirkan memiliki berat badan kurang dari normal (Sujianti, 2018). Wanita umur $<20$ tahun sel telurnya belum begitu matang sehingga dikhawatirkan bayi yang dilahirkan mengalami kecacatan fisik, perdarahan, bayi lahir prematur dan Berat badan lahir rendah serta tekanan darah tinggi (Rahayu et al., 2018).

Secara psikis, umumnya remaja belum siap menjadi ibu. Selain tidak ada persiapan, kehamilannya pun tidak dipelihara dengan baik. Emosi dan kejiwaannnya belum cukup matang sehingga pada saat kehamilan ibu tersebut belum dapat menanggapi kehamilannya secara sempurna dan sering terjadi komplikasi (Khoiriah, 2017). Pada kehamilan dengan usia muda ditemukan beberapa permasalahan diantaranya kekurangan kondisi sosial seperti status sosial ekonomi rendah, rendahnya pendidikan ibu, gizi buruk dan indeks masa tubuh yang rendah. Risiko kehamilan pada ibu yang terlalu muda usia biasanya timbul karena mereka belum siap secara psikis maupun fisik (Sujianti, 2018).

Kehamilan diatas usia 35 tahun juga tidak dianjurkan karena kondisi tubuh dan kesehatannya sudah mulai menurun sehingga dapat mempengaruhi janin intra uteri dan dapat menyebabkan kelahiran BBLR, mengingat mulai usia ini sering muncul penyakit seperti hipertensi, tumor jinak, dan penyakit degeneratif lainnya. Dalam proses persalinan sendiri, kehamilan diusia 35 tahun ke atas akan menghadapi kesulitan akibat lemahnya kontraksi rahim serta timbul kelainan pada tulang panggul(Khoiriah, 2017). Resiko melahirkan BBLR berhubungan dengan ibu bersalin usia tua mengarah ke faktor biologis seperti anomali kromosom, pre eklampsia, dan diabetes melitus (Sujianti, 2018).

b. Faktor risiko paritas Ibu pada BBLR

Tabel 3 menunjukkan data tabulasi silang antara faktor risiko paritas dengan derajat BBLR. Mayoritas bayi BBLR dilahirkan oleh ibu multigravida sebanyak 37 bayi dari 75 BBLR. Hasil uji statistik menggunakan spearmen rank menunjukkan hasil $p=0,126>0,05$ artinya tidak ada hubungan antara paritas dengan derajat BBLR. Sejalan dengan penelitian Supiati, 2016 yang menunjukkan tidak ada hubungan antara paritas ibu dengan BBLR(Supiati, 2016). Akan tetapi hasil ini bertentangan dengan penelitian lain yang menyatakan bahwa ada hubungan antara paritas ibu dengan derajat BBLR(Dwi Ertiana, 2020).

Paritas adalah jumlah kelahiran hidup yang pernah dilalui ibu, baik bayi tunggal maupun bayi kembar. Pada masa kehamilan, rahim ibu teregang oleh adanya janin, apabila jumlah paritas kecil maka otot uterus masih kuat dan kekuatan mengejan belum berkurang sehingga risiko komplikasi persalinan maupun partus lama yang dapat membahakan ibu maupun janin dapat berkurang. Sedangkan apabila ibu terlalu sering melahirkan maka rahim akan semakin lemah. Ibu yang telah melahirkan tiga anak atau lebih akan cenderung mengalami gangguan pada waktu kehamilan, persalinan dan nifas (Kementrian Kesehatan RI, 2011).

BBLR dengan faktor risiko paritas terjadi karena sistem reproduksi ibu sudah mengalami penipisan akibat sering melahirkan. Hal ini disebabkan oleh semakin tinggi paritas 
ibu, kualitas endometrium akan semakin menurun. Kehamilan yang berulang-ulang akan mempengaruhi sirkulasi nutrisi ke janin dimana jumlah nutrisi akan berkurang dibandingkan dengan kehamilan sebelumnya (Mahayana et al., 2015). Hal tersebut mengakibatkan paritas menjadi salah satu faktor risiko yang terjadinya BBLR. Ibu multipara lebih berisiko melahirkan BBLR(Merklinger-Gruchala et al., 2019).

Ibu yang pernah melahirkan anak lebih dari tiga kali beresiko melahirkan bayi BBLR, hal ini di karenakan keadaan rahim biasanya sudah lemah dikarenakan oleh alat-alat reproduksi yang sudah menurun sehingga sel-sel otot mulai melemah dan bagian tubuh lainnya sudah menurun sehingga dapat menyebabkan dan meningkatkan kejadian BBLR. Kehamilan yang berulang-ulang akan menyebabkan kerusakan pada dinding pembuluh darah uterus, hal ini akan mempengaruhi nutrisi ke janin pada kehamilan selanjutnya sehingga dapat menyebabkan gangguan pertumbuhan janin yang selanjutnya akan melahirkan bayi dengan BBLR (Khoiriah, 2017). Paritas merupakan faktor resiko tinggi penyebab BBLR, dimana ibu dengan paritas $>3$ anak akan beresiko 2 kali melahirkan BBLR. Bila seorang wanita terlalu sering melahirkan, rahimnya akan menjadi semakin melemah karena jaringan parut uterus terbentuk akibat kehamilan berulang. Jaringan parut ini akan menyebabkan kekurangan persediaan darah ke plasenta, akibatnya pertumbuhan janin bisa terganggu (Utami, 2017).

\section{SIMPULAN}

Mayoritas Bayi Berat Lahir Rendah (BBLR) berdasarkan derajatnya masuk kategori BBLR dengan berat badan bayi 1500-2499 gram yaitu sebanyak 67 bayi (89,33\%). Secara statistik di penelitian ini menunjukkan tidak ada hubungan antara faktor risiko umur Ibu dan paritas.

\section{SARAN}

Saran untuk ibu hamil untuk melakukan pemeriksaan kehamilan minimal 4 kali selama kehamilan untuk mengetahui kesehatan ibu dan janin sehingga dapat dilakukan tatalaksana dengan segera jika ada permasalahan dalam kehamilan dan menghindari faktor resiko yang dapat menyebabkan terjadinya BBLR.

\section{REFERENCE}

Aryastami, N. K., \& Tarigan, I. (2017). Kajian Kebijakan dan Penanggulangan Masalah Gizi Stunting di Indonesia. Buletin Penelitian Kesehatan, 45(4), 233-240.

Bhaskar, R. K., Deo, K. K., Neupane, U., Chaudhary Bhaskar, S., Yadav, B. K., Pokharel, H. P., \& Pokharel, P. K. (2015). A Case Control Study on Risk Factors Associated with Low Birth Weight Babies in Eastern Nepal. International Journal of Pediatrics, 2015, 1-7. https://doi.org/10.1155/2015/807373

Choiriyah, M., Hapsari, E. D., Lismidiati, W., Studi, P., Keperawatan, I., Kedokteran, F., Brawijaya, U., Studi, P., Keperawatan, M., Kedokteran, F., \& Mada, U. G. (2015). Tradisi dan Lingkungan Sosial Memengaruhi Dukungan Menyusui pada Bayi Berat Badan Lahir Rendah di Kota Malang Tradition and Social Environment Influence Breastfeeding Support on Low Birthweight in Malang. Jurnal Kesehatan Masyarakat Nasional, 10(1), 37-43.

Dinas Kesehatan DIY. (2020). Profil Kesehatan D.I. Yogyakarta tahun 2019. In Dinas Kesehatan DIY.

Dwi Ertiana. (2020). Usia dan Paritas Ibu dengan Insidence dan Derajat Bayi Baru Lahir (BBLR). Embrio, 12(2), 66-78. https://doi.org/10.36456/embrio.v12i2.2523

Ekowati, D., Ani, L. S., \& Windiani, I. G. A. T. (2017). High parity and chronic energy deficiency increase risk for low birth weight in Situbondo District. Public Health and Preventive Medicine Archive, 5(1), 28. https://doi.org/10.15562/phpma.v5i1.38 
Kementerian Kesehatan Republik Indonesia. (2018). Warta Kesmas - Cegah Stunting Itu Penting. Warta Kesmas, 02, 1-27.

Kementerian Perencanaan dan Pembangunan Nasional. (2019). Peta Jalan SDGs Indonesia 2030. http://sdgs.bappenas.go.id/wpcontent/uploads/2020/08/Roadmap_Bahasa-Indonesia_File-Upload.pdf

Kementrian Kesehatan RI. (2011). Buku Pedoman Pengenalan Tanda Bahaya pada Kehamilan, Persalinan dan Nifas. Kementrian Kesehatan RI.

Kementrian Kesehatan RI. (2020). Profil Kesehatan Indonesia Tahun 2019. In Kementrian Kesehatan Repoblik Indonesia.

Khoiriah, A. (2017). Hubungan Antara Usia Ibu dan Paritas Ibu Bersalin dengan Berat Bayi Lahir Rendah (BBLR) Di RS. Siti Khadijah Palembang. Jurnal Kesehatan, 8(2), 310314. http://dx.doi.org/10.35842/jkry.v5i2.201

Kosim MS, Yunanto A, Dewi R, Sarosa GI, U. A. (2012). Buku Ajar Neonatologi. Ikatan Dokter Anak Indonesia.

Mahayana, S. A. S., Chundrayetti, E., \& Yulistini, Y. (2015). Faktor Risiko yang Berpengaruh terhadap Kejadian Berat Badan Lahir Rendah di RSUP Dr. M. Djamil Padang. Jurnal Kesehatan Andalas, 4(3), 664-673. https://doi.org/10.25077/jka.v4i3.345

Makbruri. (2015). Faktor Risiko yang Memengaruhi Berat Badan Lahir Rendah dan Sangat Rendah di Kecamatan Seberang Ulu II Kota Palembang Periode 1 Januari-31 Desember 2008. Jurnal Gradien, 11(1), 1079-1084. https://ejournal.unib.ac.id/index.php/gradien/article/view/741

Merklinger-Gruchala, A., Jasienska, G., \& Kapiszewska, M. (2019). Paternal investment and low birth weight - The mediating role of parity. PLoS ONE, 14(1), 1-14. https://doi.org/10.1371/journal.pone.0210715

Mitra, M. (2014). Berat Badan Lahir Rendah, Solusi dan Dampak yang Ditimbulkannya. Jurnal Kesehatan Komunitas, 2(5), 191-192. https://doi.org/10.25311/keskom.vol2.iss5.149

Rahayu, A., Km, S., \& Ph, M. (2018). Buku Ajar Gizi 1000 Hari Pertama Kehidupan.

Rahayu, Y., Basit, M., \& Silvia, M. (2015). Hubungan Usia Ibu Dengan Bayi Berat Badan Lahir Rendah (Bblr) Di Rsud Dr. H. Moch. Ansari Saleh Banjarmasin Tahun 2013-2014. Dinamika Kesehatan, 5(2), 0-9.

Siramaneerat, I., Agushybana, F., \& Meebunmak, Y. (2018). Maternal Risk Factors Associated with Low Birth Weight in Indonesia. The Open Public Health Journal, 11(1), 376-383. https://doi.org/10.2174/1874944501811010376

Sujianti. (2018). Correlation Between Age Of Mother With Low Birth Weight Babies (Lbw) In Cilacap Hospital. Jurnal Kesehatan Al-Irsyad (JKA), XI(1), 62-67.

Supiati, S. (2016). Karakteristik Ibu Kaitannya Dengan Kejadian Bayi Berat Badan Lahir Rendah. Jurnal Kebidanan Dan Kesehatan Tradisional, 1(1), 64-68. https://doi.org/10.37341/jkkt.v1i1.69

Utami, U. (2017). Hubungan Antara Preeklamsia Berat dengan BBLR di RS Dr. Oen Surakarta. Universitas Muhammadiyah Surakarta.

Yuliawati, R., Kurniasari, L., \& Maryam, S. (2018). Hubungan antara pendidikan dan dukungan keluarga dengan kegagalan asi eksklusif Relationship between education and family support with exclusive asi failure. Jurnal Health of Studies, 3(2), 79-86. 